\title{
Predictive Factors of Bladder Tumor Recurrence after Nephro-Ureterectomy for Urothelial Carcinoma
}

\author{
John David Rebibo, Emeric Lacarrière, Francois Xavier Nouhaud, Athmane Safsaf, \\ Romain Caremel, Christian Pfister*
}

Department of Urology, Rouen University Hospital, Rouen, France

Email: ${ }^{*}$ christian.pfister@chu-rouen.fr

Received 5 January 2015; accepted 27 January 2015; published 29 January 2015

Copyright (C) 2015 by authors and Scientific Research Publishing Inc.

This work is licensed under the Creative Commons Attribution International License (CC BY).

http://creativecommons.org/licenses/by/4.0/

(c) (i) Open Access

\section{Abstract}

Objectives: To evaluate the incidence of bladder cancer after nephro-ureterectomy (NUT) and determine the potential risk factors of bladder recurrence in patients with upper urinary tract urothelial carcinoma (UUT-UC). Materials and Methods: We retrospectively assessed 37 patients with UUT-UC including a significant follow-up after NUT of 34 months (range 12 - 120 months). The median age of the population was 72 years (range 48 - 83 years). Patients with a previous history of bladder cancer, concomitant diagnosis of bladder tumor and UUT-UC; or a metastatic UUTUC were excluded from the study. Results: Out of these 37 patients, 17 presented a bladder recurrence within an average time of 12 months (range 3 to 31 months) after the NUT. In $94 \%$ of the cases, bladder recurrence occurred within the first 24 months following the NUT. Histological distribution was: 13 Ta tumors (76\%), 2 pT1 tumors (11.7\%); 11 patients had a high stage lesion (76\%), whereas 4 patients had a low stage lesion (23.5\%). As regards the anatomo-pathological characteristics of the UUT-UC, the supra iliac localization of the tumor is a significant risk factor of bladder recurrence $(p=0.04)$. Conclusion: Bladder recurrence after NUT occurred frequently and could have possibly been under-estimated. The use of intra-vesical instillation of Mitomycin $C$ after NUT has been recently recommended by the European Association of Urology, but no predictive factors have yet been identified. Early diagnosis of bladder recurrence could certainly have reduced mortality in this patient population.

\section{Keywords}

Bladder Recurrence, Nephro-Ureterectomy, Urothelial Carcinoma

\footnotetext{
${ }^{*}$ Corresponding author.
} 


\section{Introduction}

Upper urinary tract urothelial carcinoma (UUT-UC) remains a rare pathology, with an annual incidence of 1 to 2 cases out of 100,000 [1]-[3]. During the diagnosis, $10 \%$ to $15 \%$ of patients have been detected to have synchronal bladder tumors [1]-[3], whereas 15\% to $40 \%$ of patients developed bladder tumor recurrence within 18 to 24 months [2]-[4]. The presence of this type of lesion at diagnosis or during the clinical follow-up is a significant prognostic factor [5]. Nephro-ureterectomy (NUT) combined with an excision of the bladder cuff in order to avoid any bladder tumor recurrence remains the gold standard treatment [6]. Various studies have reported predictive factors for bladder tumor recurrence: i.e. the multifocality of the lesions; previous medical history of bladder tumor; concomitant in situ carcinoma [7]-[11]; tumor stage with lesions > pT2 [9] [10]; high stage tumors [12] [13]; size of the lesion > $5 \mathrm{~cm}$ [9]; ureteral localization; and whether the NUT was performed by open surgery or laparoscopy [9]. Two theories may explain the multifocality of the tumor as well as the risk of UUTUC bladder recurrence. First, is the implantation of desquamated epithelial cells by the tumor present in the urine flow. Secondly, UUT-UC is considered as a general disease of the urothelium based on the field effect theory. Our objectives were to not only to evaluate the incidence of bladder cancer after NUT but also determine the potential risk factors of bladder recurrence in patients with upper urinary tract urothelial carcinoma.

\section{Materials and Methods}

We retrospectively assessed a series of UUT-UC patients who had undergone a NUT between January 2000 and March 2011. During this period, different urologists were involved in the management of the NUT. Surgical indication and clinical follow-up was validated by a multidisciplinary team based on the recommendations of the Oncology Committee of the French Association of Urology (CCAFU). Post-operative cystoscopy and urinary cytology were performed every 6 months for 2 years, and finally every year for 5 years; an abdominal-pelvic CT scan examination with late post-injection was carried-out every 2 years [3]. The exclusion criteria were: the patients with a previous history of bladder carcinoma (20 patients), diagnosis of concomitant bladder tumor with upper urinary tract urothelial carcinoma (4 patients), metastatic UUT-UC (8 patients) and the patients with a follow-up less than 12 months after the NUT (6 patients). A total of 37 patients were included with a median follow-up of 34 months (range 12 to 120 months). The NUT was routinely performed with an excision of the bladder cuff, by lombotomy (20 patients) or by laparoscopy (17 patients) via an iliac approach. TNM classification was used for the urinary tract urothelial carcinoma and the bladder tumors. The tumor stage (OMS classification), the size of the lesion and its multifocality were also evaluated based on an histological examination of the biopsy tissues [3]. All data were collected on Excel 2007 and the statistical analysis was performed with SAS software (version 9.3). Correlations on clinical and pathological levels were tested, using the Student's-ttest as regards the quantitative variables, and the Chi-squared test for qualitative variables.

\section{Results}

Among the 37 patients included in this study, 17 patients (46\% of the cases) developed a bladder tumor recurrence within an average period of 12 months (range 3 - 31 months) after the NUT and 94\% of them had a bladder recurrence within the two following years (Figure 1). The average age of the patients diagnosed with UUT-UC was 72 years (range 48 to 83 years), with a sex ratio of 2:1 (25 men and 12 women). The average age of the population with a bladder recurrence was 68.76 years (standard deviation 9.98). In our series, UUT-UC lesion was in the supra iliac ureter for 21 patients (52.5\%) in the subiliac ureter for 19 patients (47.5\%). When there was a bladder tumor recurrence, the histological distribution was: 13 patients pTa tumors (76\%), 2 pT1 tumors (11.7\%), 11 patients had a high stage lesion (64\%) whereas 4 patients a low stage lesion (23.5\%) (Table 1). We also assessed UUT-UC primitive lesion characteristics for the 17 patients with bladder tumor recurrence: in 82\% of the cases, the tumor was low stage (14 patients) and in 3 cases the lesion was high stage (17.65\%). Only one case of bladder recurrence had an in situ carcinoma. Moreover, 2 patients who were highly suspected to develop tumor recurrence died before the final histological diagnosis, they were not included in the 17 patients with bladder tumor recurrence. The UUT-UC localized in the supra iliac ureter had a higher risk of bladder recurrence $(p=0.04)$. We observed that $64 \%$ of the bladder tumors were at the same time high stage and mutlifocal tumors (Table 2). As regards bladder recurrence topography, we noted that $47 \%$ of the lesions were found on the NUT homolateral bladder lateral side, whereas in 3 cases the bladder recurrence was situated near the area of 


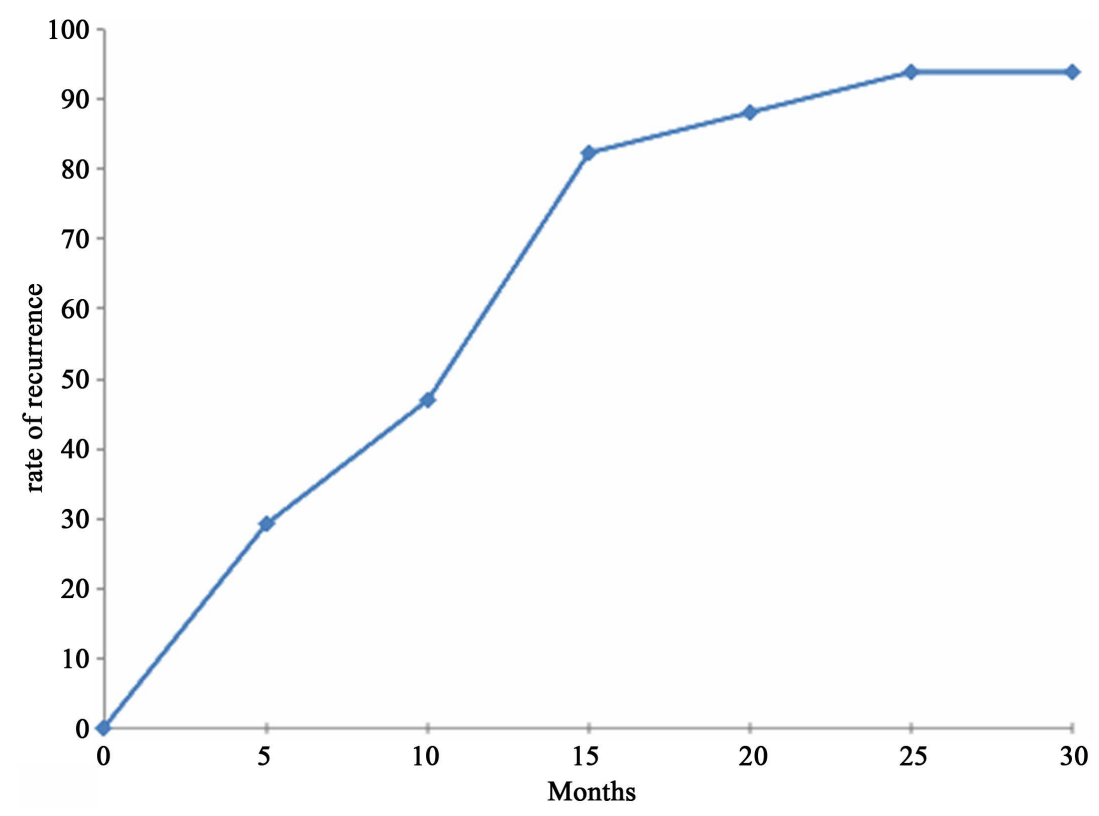

Figure 1. Timeline of the first bladder recurrence after NUT.

Table 1. Characteristics of the population.

\begin{tabular}{|c|c|}
\hline Variables & Nombre de Patients \\
\hline \multicolumn{2}{|l|}{ Age (years) } \\
\hline$<70$ ans & $15(40.54 \%)$ \\
\hline $70-79$ ans & $14(37.83 \%)$ \\
\hline$>79$ ans & $8(21.6 \%)$ \\
\hline \multicolumn{2}{|l|}{ Sex } \\
\hline Male & $25(64 \%)$ \\
\hline Female & 12 (36\%) \\
\hline \multicolumn{2}{|c|}{ Side of the tumor } \\
\hline Right & 20 (51.28\%) \\
\hline Left & $17(48.72 \%)$ \\
\hline \multicolumn{2}{|c|}{ Tumor localization } \\
\hline Subiliac & 19 (47.5\%) \\
\hline Supra iliac & $21(52.5 \%)$ \\
\hline \multicolumn{2}{|c|}{ Type of the surgery } \\
\hline Laparoscopy & 17 (45.9\%) \\
\hline Lombotomy & $20(54 \%)$ \\
\hline \multicolumn{2}{|l|}{ Tumor stage } \\
\hline рТа & $11(29.7 \%)$ \\
\hline pT1 & 10 (27.02\%) \\
\hline pT2 & $6(16.21 \%)$ \\
\hline рT3 & $9(24.32 \%)$ \\
\hline pT4 & $1(2.7 \%)$ \\
\hline \multicolumn{2}{|l|}{ Grade } \\
\hline Hight & 31 (83.78\%) \\
\hline Low & $6(16.2 \%)$ \\
\hline \multicolumn{2}{|c|}{ Uni/Multifocality } \\
\hline Uni focal & 34 (91.89\%) \\
\hline Multifocal & $3(8.1 \%)$ \\
\hline \multicolumn{2}{|l|}{ Tumor size } \\
\hline$<3 \mathrm{~cm}$ & $12(32.42 \%)$ \\
\hline$>3 \mathrm{~cm}$ & $25(67.56 \%)$ \\
\hline
\end{tabular}


ureteral meatus resection. Finally, we did not observe any significant difference in the clinical-pathological characteristics between the two groups (Table 2). After the diagnosis of bladder recurrence, a radical cystectomy was required for 6 patients following endovesical bacillus Calmette-Guérin (BCG) therapy failure and/or tumor progression. As our database was established prior to the 2013 guidelines, no patient had immediate post-operative instillation of Mitomycin C. Nevertheless, 7 patients underwent adjuvant intravesical chemotherapy.

\section{Discussion}

The bladder is the main localization of tumor recurrence once the patient has been treated for urinary upper tract urothelial carcinoma (UUT-UC). Hirano et al. reported a bladder recurrence after a NUT in $34 \%$ of cases within an average period of 6.5 months (range 2.8 - 57.3 months) [14]. In most cases, the diagnosis was made during the two first years of follow-up care: 45\% (23 patients) had a pTa grade bladder lesion and 12 patients (23.5\%) had a pT1 grade tumor. In a cohort of 482 patients treated by NUT for UUT-UC, Xylinas et al. observed that 35\% of patients had a bladder recurrence with a median follow-up care of 39.5 months [15]. The results of our retrospective single-center series are in agreement data previously reported in literature. The primary challenge for a urologist remains the identification of high-risk patients, in order to prevent both bladder recurrence and any tumor progression. The importance of clinical-pathological parameters, i.e. tumor stage, cellular grade, localization of the UUT-UC, tumor multifocality and presence of carcinoma in situ has been demonstrated by different authors [7] [9] [10] [12] [14] and also observed in our series. Moreover, Pignot et al. in a retrospective study of 662 cases of NUT underlined that 83 patients (12.5\%) had previous bladder cancer, 62 patients (9.4\%) exhibited

Table 2. Comparison of the clinical and pathological characteristics between patients who had a bladder recurrence after nephro-ureterectomy (NUT) with those who had no recurrence.

\begin{tabular}{|c|c|c|c|}
\hline & No bladder recurrence $(\mathrm{n}=20)$ & Bladder recurrence $(\mathrm{n}=17)$ & $\mathrm{p}$ \\
\hline Age & $72.85 \pm 7.69$ & $68.76 \pm 9.98$ & 0.168 \\
\hline $\begin{array}{c}\text { Sex } \\
\text { Male } \\
\text { Female }\end{array}$ & $\begin{array}{l}12(60 \%) \\
8(40 \%)\end{array}$ & $\begin{array}{c}13(76.47 \%) \\
4(23.53 \%)\end{array}$ & 0.2862 \\
\hline $\begin{array}{l}\text { Side } \\
\text { Right } \\
\text { Left }\end{array}$ & $\begin{array}{c}13(65 \%) \\
7(35 \%)\end{array}$ & $\begin{array}{c}7(41.18 \%) \\
10(58.82 \%)\end{array}$ & 0.1473 \\
\hline $\begin{array}{c}\text { Tumor localization } \\
\text { Supra iliac } \\
\text { Sub iliac }\end{array}$ & $\begin{array}{l}10(50 \%) \\
10(50 \%)\end{array}$ & $\begin{array}{c}14(82.3 \%) \\
3(17.7 \%)\end{array}$ & 0.040 \\
\hline Tumor size $(\mathrm{mm})$ & $32.22 \pm 12.44$ & $38.56 \pm 11.56$ & 0.135 \\
\hline $\begin{array}{c}\text { Surgical procedure } \\
\text { Laparoscopy } \\
\text { Lombotomy }\end{array}$ & $\begin{array}{c}9(45 \%) \\
11(53 \%)\end{array}$ & $\begin{array}{l}7(43.75 \%) \\
9(56.25 \%)\end{array}$ & 0.9402 \\
\hline $\begin{array}{l}\text { Grade } \\
\text { High } \\
\text { Low }\end{array}$ & $\begin{array}{c}3(11 \%) \\
17(85 \%)\end{array}$ & $\begin{array}{c}3(17.65 \%) \\
14(82.35 \%)\end{array}$ & 0.8277 \\
\hline Vascular embols & $9(45 \%)$ & $4(23.53 \%)$ & 0.1728 \\
\hline Tumoral necrosis & $2(10 \%)$ & $1(6.25 \%)$ & 0.6858 \\
\hline $\begin{array}{c}\text { Tumor stage } \\
\text { pTa } \\
\text { pT1 } \\
\text { pT2 } \\
\text { pT3 } \\
\text { pT4 }\end{array}$ & $\begin{array}{c}2(10 \%) \\
8(40 \%) \\
3(15 \%) \\
6(30 \%) \\
1(5 \%)\end{array}$ & $\begin{array}{c}8(47.06 \%) \\
3(17.65 \%) \\
3(17.65 \%) \\
3(17.65 \%) \\
0(0 \%)\end{array}$ & 0.1040 \\
\hline $\begin{array}{c}\text { Uni/Multifocality } \\
\text { Unif ocal } \\
\text { Multifocal }\end{array}$ & $\begin{array}{c}19(95 \%) \\
1(5 \%)\end{array}$ & $\begin{array}{c}15(88.24 \%) \\
2(11.76 \%)\end{array}$ & 0.4525 \\
\hline
\end{tabular}


concomitant bladder tumor with the diagnosis of UUT-UC and 75 patients (11.3\%) presented with both previous and current bladder cancer (BC). The patients with associated BC had more tumors located in the ureter, as well as more multiple locations in the upper urinary tract $(\mathrm{p}<0.0001)$. Nevertheless, the presence of UUT-UC with no previous or synchronous BC did not significantly affect the specific cancer survival rates after nephrouretectomy [16].

The early post-operative instillation of Mitomycin C (IPOP) after trans-urethral bladder resection is a treatment that has been validated for the management of non muscle invasive bladder cancer (NMIBC), that could decrease the risk of tumor recurrence by $12 \%$ to $39 \%$, whether the lesion is uni or multi-focal [17]. A randomized study by O'Brien et al. suggested evaluating the usefulness of Mitomycin C instillation, in a series of 284 patients, on the very same day as the removal of the bladder catheter after NUT [18]. The rate of tumor recurrence reported was substantially lower in the group of treated patients, compared with the group of monitored patients $(17 \%$ vs. $27 \%, p=0.055)$. These authors suggested that an instillation of IPOP would be required for an average of 10 patients in order to avoid a bladder recurrence during the standard follow-up of a UUT-UC. Subsequently, the results of this study allowed to recently modify the guidelines of the European Association of Urology by recommending an early instillation of Mitomycin C after NUT for UUT-UC [19]. In our retrospective study, no patient benefited from an early instillation of Mitomycin C as our database was established prior to the 2013 recommendations.

In contrast, a number of prospective studies showed the superiority of fluorescence by blue-light-illuminated cystoscopy compared with standard cystoscopy concerning the detection of NMIBC [20]. More recently, Burger's meta-analysis (8 studies with a total of 2160 patients) confirmed that cystoscopy with blue light illumination using hexamino-levulinic acid $\left(\right.$ Hexvix $\left.^{\circledR}\right)$ would first allow a better diagnosis of the different NMIBC (pTa, pT1 grades and above all carcinoma in situ (CIS)) and would also decrease by $24 \%$ the risk of bladder recurrence after 12 months [21]. In the literature, the rate of bladder tumor recurrence after NUT has often been under-estimated. According to the authors, a better endoscopic evaluation of the bladder seems to be necessary at diagnosis and during the follow-up of UUT-UC. Also, as previously described, including IPOP in the management of these tumors is certainly very interesting, however the use of blue-light-illuminated cystoscopy appears essential for high grade tumors to detect associated CIS.

It is important to remember that the survival of a UUT-UC after NUT decreases when there is a bladder tumor recurrence: In fact, the specific survival rate seems to be linked with the characteristics of the bladder recurrence, the infiltrating character of the bladder tumor being a negative factor. Rink et al. evaluated the survival after a UUT-UC recurrence treated by NUT in 596 patients: the average time between tumor recurrence and death was 10 months ( $80 \%$ of the patients died within the 2 years following the diagnosis of bladder tumor recurrence [22].

\section{Conclusion}

A new medical treatment approach is required in order to improve the detection of bladder recurrence and the survival rate specific to the UUT-UC after NUT. Immediate post-operative instillation in the bladder after NUT has been recently recommended by the European Association of Urology.

\section{Acknowledgements}

The authors are grateful to Richard Medeiros, Medical Editor of Medical Editing International for his valuable editing of the manuscript.

\section{Conflict of Interest}

None.

\section{References}

[1] Jemal, A., Siegel, R., Ward, E., Hao, Y., Xu, J. and Thun, M.J. (2009) Cancer Statistics, 2009. CA: A Cancer Journal for Clinicians, 59, 225-249. http://dx.doi.org/10.3322/caac.20006

[2] Roupret, M., Wallerand, H., Traxer, O., Roy, C., Mazerolles, C., Saint, F., et al. (2010) Check up and Management of Upper Urinary Tract Tumors in 2010: An Update from the Committee of Cancer from the French National Association of Urology. Progres en Urologie, 20, 260-271. 
[3] Pfister, C., Roupret, M., Wallerand, H., Davin, J.L., Quintens, H., Guy, L., et al., Oncology Committee of the French Association of Urology (CCAFU) (2010) Recommendations Onco-Urology 2010: Urothelial Tumors. Progres en Urologie, 20, S255-S274. http://dx.doi.org/10.1016/S1166-7087(10)70043-9

[4] Messing, E.M. and Catalona, W. (1998) Urothelial Tumors of the Urinary Tract. In: Walsh, P.C., Retik, A.B., Vaughan, E.D. and Wein, A.J., Eds., Campbell's Urology, WB Saunders, Philadelphia, 2327-2410.

[5] Mullerad, M., Russo, P., Golijanin, D., Chen, H.N., Tsai, H.H., Donat, S.M., et al. (2004) Bladder Cancer as a Prognostic Factor for Upper Tract Transitional Cell Carcinoma. Journal of Urology, 172, 2177-2181.

[6] Kirkali, Z. (2003) Transitional Cell Carcinoma of the Ureter and Renal Pelvis. Critical Reviews in Oncology/Hematology, 47, 155-169. http://dx.doi.org/10.1016/S1040-8428(03)00079-9

[7] Hisataki, T., Miyao, N., Masumori, N., Takahashi, A., Sasai, M., Yanase, M., et al. (2000) Risk Factors for the Development of Bladder Cancer after Upper Tract Urothelial Cancer. Urology, 55, 663-667. http://dx.doi.org/10.1016/S0090-4295(99)00563-4

[8] Kang, C.H., Yu, T.J., Hsieh, H.H., Yang, J.W., Shu, K., Huang, C.C., et al. (2003) The Development of Bladder Tumors and Contralateral Upper Urinary Tract Tumors after Primary Transitional Cell Carcinoma of the Upper Urinary Tract. Cancer, 98, 1620-1626. http://dx.doi.org/10.1002/cncr.11691

[9] Lughezzani, G., Burger, M., Margulis, V., Matin, S.F., Novara, G., Roupret, M., et al. (2012) Prognostic Factors in Upper Urinary Tract Urothelial Carcinomas: A Comprehensive Review of the Current Literature. European Urology, 62, 100-114. http://dx.doi.org/10.1016/j.eururo.2012.02.030

[10] Terakawa, T., Miyake, H., Muramaki, M., Takenaka, A., Hara, I. and Fujisawa, M. (2008) Risk Factors for Intravesical Recurrence after Surgical Management of Transitional Cell Carcinoma of the Upper Urinary Tract. Urology, 71, 123127. http://dx.doi.org/10.1016/j.urology.2007.08.054

[11] Milojevic, B., Djokic, M., Sipetic-Grujicic, S., Milenkovic-Petronic, D., Vuksanovic, A., Dragicevic, D., et al. (2011) Bladder Cancer after Managing Upper Urinary Tract Transitional Cell Carcinoma: Risk Factors and Survival. International Urology and Nephrology, 43, 729-735. http://dx.doi.org/10.1007/s11255-011-9902-4

[12] Huang, W.W., Huang, H.Y., Liao, A.C., Shiue, Y.L., Tai, H.L., Lin, C.M., et al. (2009) Primary Urothelial Carcinoma of the Upper Tract: Important Clinicopathological Factors Predicting Bladder Recurrence after Surgical Resection. Pathology International, 59, 642-649. http://dx.doi.org/10.1111/j.1440-1827.2009.02420.x

[13] Zigeuner, R.E., Hutterer, G., Chromecki, T., Rehak, P. and Langner, C. (2006) Bladder Tumour Development after Urothelial Carcinoma of the Upper Urinary Tract Is Related to Primary Tumour Location. BJU International, 98, 11811186. http://dx.doi.org/10.1111/j.1464-410X.2006.06519.X

[14] Hirano, D., Okada, Y., Nagane, Y., Satoh, K., Mochida, J., Yamanaka, Y., et al. (2012) Intravesical Recurrence after Surgical Management of Urothelial Carcinoma of the Upper Urinary Tract. Urology International, 89, 71-77. http://dx.doi.org/10.1159/000338644

[15] Xylinas, E., Colin, P., Audenet, F., Phe, V., Cormier, L., Cussenot, O., et al. (2013) Intravesical Recurrence after Radical NephroUreterectomy for Upper Tract Urothelial Carcinomas: Predictors and Impact on Subsequent Oncological Outcomes from a National Multicenter Study. World Journal of Urology, 31, 61-68. http://dx.doi.org/10.1007/s00345-012-0957-3

[16] Pignot, G., Colin, P., Zerbib, M., Audenet, F., Soulie, M., Hurel, S., et al. (2013) For the French Collaboration National Database on UUT-UC. World Journal of Urology.

[17] Sylvester, R.J., Oosterlinck, W. and van der Meijden, A.P. (2004) A Single Immediate Postoperative Instillation of Chemotherapy Decreases the Risk of Recurrence in Patients with Stage Ta T1 Bladder Cancer: A Meta-Analysis of Published Results of Randomized Clinical Trials. Journal of Urology, 171, 2186-2190. http://dx.doi.org/10.1097/01.ju.0000125486.92260.b2

[18] O’Brien, T., Ray, E., Singh, R., Coker, B. and Beard, R., British Association of Urological Surgeons Section of Oncology (2011) Prevention of Bladder Tumours after Nephro-Ureterectomy for Primary Upper Urinary Tract Urothelial Carcinoma: A Prospective, Multicentre, Randomised Clinical Trial of a Single Postoperative Intravesical Dose of Mitomycin C (the ODMIT-C Trial). European Urology, 60, 703-710. http://dx.doi.org/10.1016/j.eururo.2011.05.064

[19] Roupret, M., Babjuk, M., Comperat, E., Zigeuner, R., Sylvester, R., Burger, M., et al. (2013) European Guidelines on Upper Tract Urothelial Carcinomas: 2013 Update. European Urology, 63, 1059-1071.

http://dx.doi.org/10.1016/j.eururo.2013.03.032

[20] Fradet, Y., Grossman, H.B., Gomella, L., Lerner, S., Cookson, M., Albala, D., et al., PC B302/01 Study Group (2007) A Comparison of Hexaminolevulinate Fluorescence Cystoscopy and White Light Cystoscopy for the Detection of Carcinoma in Situ in Patients with Bladder Cancer: A Phase III, Multicenter Study. Journal of Urology, 178, 68-73. http://dx.doi.org/10.1016/j.juro.2007.03.028

[21] Burger, M., Grossman, H.B., Droller, M., Schmidbauer, J., Hermann, G., Dragoescu, O., et al. (2013) Photodynamic 
Diagnosis of Non-Muscle-Invasive Bladder Cancer with Hexaminolevulinate Cystoscopy: A Meta-Analysis of Detection and Recurrence Based on Raw Data. European Urology, 2838, 353-359.

[22] Rink, M., Sjoberg, D., Comploj, E., Margulis, V., Xylinas, E. and Lee, R.K. (2012) Risk of Cancer-Specific Mortality Following Recurrence after Radical Nephro-Ureterectomy. Annals of Surgical Oncology, 19, 4337-4344.

http://dx.doi.org/10.1245/s10434-012-2499-8 
Scientific Research Publishing (SCIRP) is one of the largest Open Access journal publishers. It is currently publishing more than 200 open access, online, peer-reviewed journals covering a wide range of academic disciplines. SCIRP serves the worldwide academic communities and contributes to the progress and application of science with its publication.

Other selected journals from SCIRP are listed as below. Submit your manuscript to us via either submit@scirp.org or Online Submission Portal.
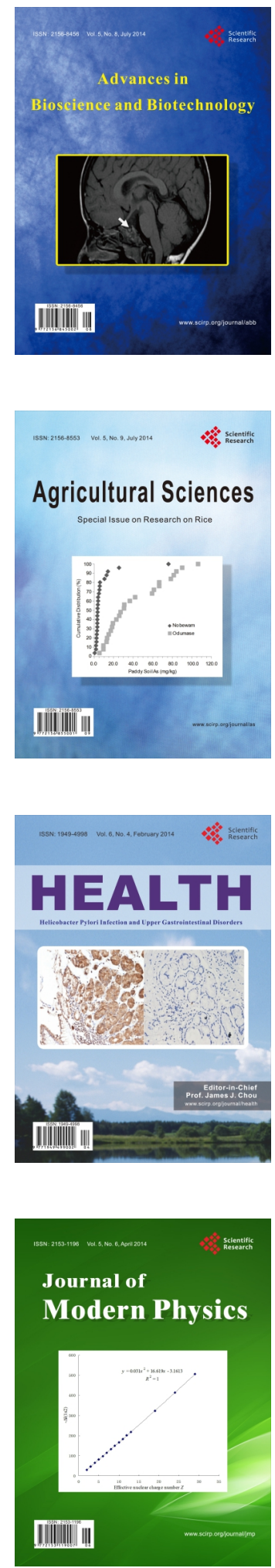
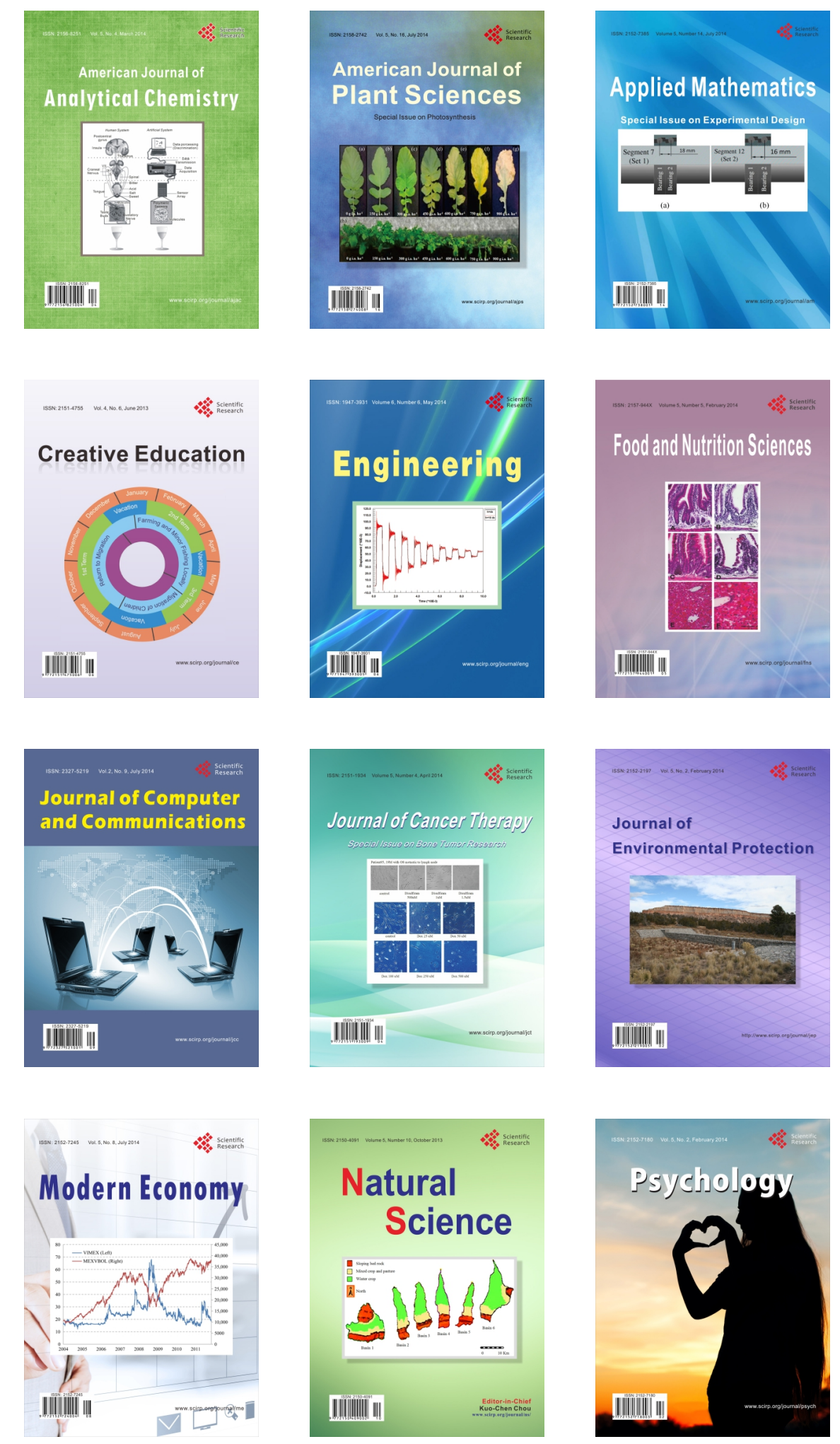